\title{
Design and Development of Fuzzy Expert System for Integrated Disease Management in Finger Millets
}

\author{
Philomine Roseline \\ Center for Research \\ Christ University \\ Bangalore, India
}

\author{
Clarence J M Tauro \\ Center for Research \\ Christ University \\ Bangalore, India
}

\author{
$\mathrm{N}$ Ganesan, $\mathrm{PhD}$. \\ Director (MCA) \\ RICM, Bangalore
}

\begin{abstract}
Expert system - a branch of Artificial Intelligence is a collection of programs which has the ability to reason, justify and answer the queries in a particular domain as a human expert would do. It can be applied to various fields. Expert system in agriculture is gathering momentum and this paper aims at tackling the control and remedial measures for disease management for the staple food crop of Karnataka - Finger Millets popularly known as Ragi. The introduction section consists of contributions of expert systems in agriculture. The second section explains the process in Integrated Disease Management (IDM).The third section is about knowledge engineering process which consists of knowledge acquisition and knowledge representation. The fourth section is about the application of fuzzy logic in IDM. The fifth section briefs about defuzzification of IDM.
\end{abstract}

\section{Keywords}

Expert System, Knowledge Base, Fuzzy Logic, Integrated Disease Management, Pathomerty.

\section{INTRODUCTION}

An expert system is a collection of software developed for a particular area of domain aimed to suggest solutions to problems in the way as human experts pertaining to that field would solve.

The basic lifeline of an expert system is the "knowledge base" which is a well-organized collection of traditional data base with more rules, facts, and practices prevalent in that domain. The most striking features of the architecture of the expert system are Inference engine and explanation facility. The inference engine uses different rules to arrive at a conclusion and the explanation facility provided justification of the conclusion. It not only infers new knowledge but also updates the knowledge base. Due to its versatility it is fast emerging as a discipline with great potential for research and development.

\section{CONTRIBUTIONS OF EXPERT SYSTEMS TO THE FIELD OF AGRICULTURE}

A study of the expert systems that were built from the seventies to till date reveals significant technological advancements in the input methods, paradigm shift in the process and more accurate output. The earlier systems (MYCIN developed in 1970s) used input method where the user has to type the answer to a series of questions, whereas the recent system uses image acquisition, spatial data through remote sensing and multimedia. Processing has seen a "paradigm shift" - wherein the earlier systems used forward or backward chain and heuristics method to process the queries, recent expert systems use fuzzy logic and multi-agent based methodology and hence the output also is more accurate than the success rate of MYCIN (65\%) which was unfortunately never put into practical use due to legal and ethical issues. Web-based systems developed have a better reach confined not only to the targeted users but has a global usage. Thus, in today's scenario expert system has become a more viable and sustainable technology applicable to the grass-root level of our society [1].

Expert systems has found a wide spectrum of application across many domains such as nursing care and medicine, natural resources management, agriculture, process control, technology in design and manufacturing, remote sensing and project management- just to name a few.

In agricultural field, a myriad of expert systems for various crops such as wheat, rice, maize, sunflower, lime, tomato, apple, orange, soybean and cucumber has been developed so far[2]. These expert systems focus on a particular problem with respect to a specific crop. Different aspects of agricultural problems were addressed such as Soil management, disease and pest management, nutrient and fertilizers management, and irrigation management.

In this paper, an expert system exclusively for the integrated disease management in finger millet is being presented by incorporating fuzzy logic method to frame the rules and apply defuzzification to attach a value to the severity of the disease identified, based on which the control and remedial measures are suggested.

\section{INTEGRATED DISEASE MANAGEMENT (IDM)}

\subsection{Basic Facts}

According to the statistics a loss of $8 \%$ is due to the diseases that attack the crop at various stages of its growth. Hence, it is crucial to devise an efficient way to tackle the problem. Combined with the expertise of the agricultural scientist and experience of the farmers, technology can be blended to revolutionize the agronomic practices [3][5].

Disease management can be defined as the series of agronomic practices to be followed so as to minimize the produce loss due to disease. It starts with identifying the diseases that affects the crop, calculating the loss it may cause and the timely application of the appropriate chemicals to exterminate the disease and recover which leads to achieve the expected yield [9][10].

'Integrated Disease Management' involves the selection and application of a harmonious range of disease control strategies that minimize losses and maximizes returns [4]. 


\section{DEVELOPMENT OF FUZZY EXPERT SYSTEM}

The system developed has various parameters to identify the disease.

Firstly, the season during which the disease has attacked early kharief, kharief, late kharief, rabi and summer must be chosen which will eliminate some of the diseases from the database.

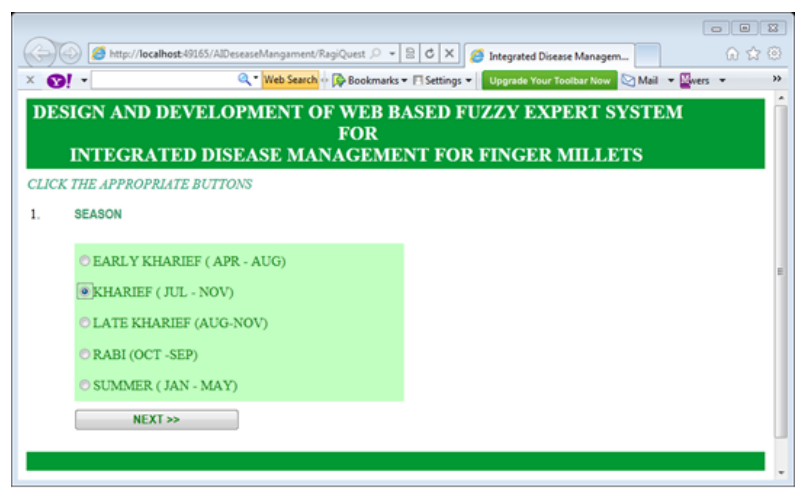

Figure 4: Identification of the season

Next, the part of the crop infected should be given as the input, such as leaf, stem, flower, finger, neck and ear, which will again eliminate the other diseases form the list.

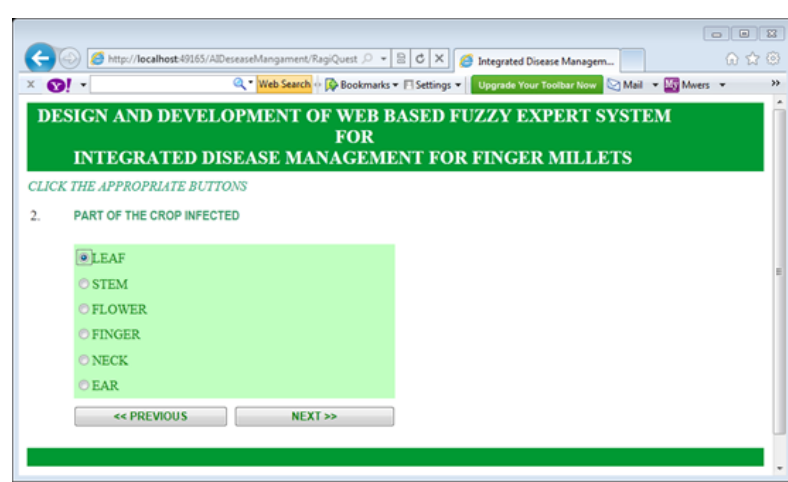

Figure 5: Identification of infected part of the plant

Next, the symptoms listed in a brief description of the appearance of the infected area is to be selected which is mentioned in the next screen as input and this in turn would further narrow down the search.

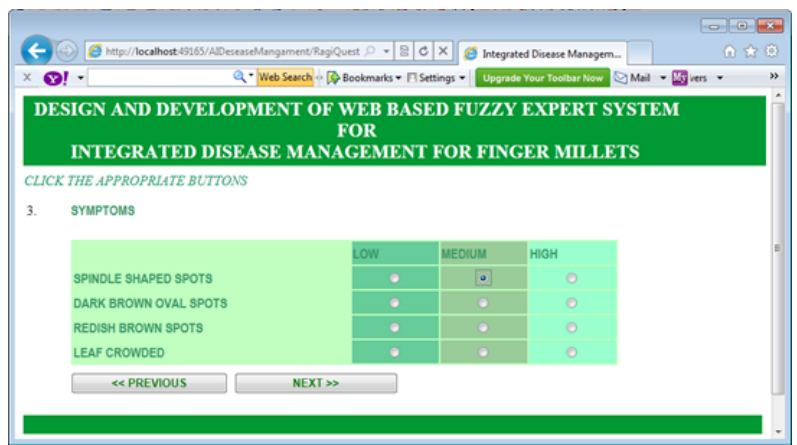

Figure 6: Identification of the level of Infection

Next, the stage of the plant must be selected since the same disease can affect the crop during various stages of the crop.

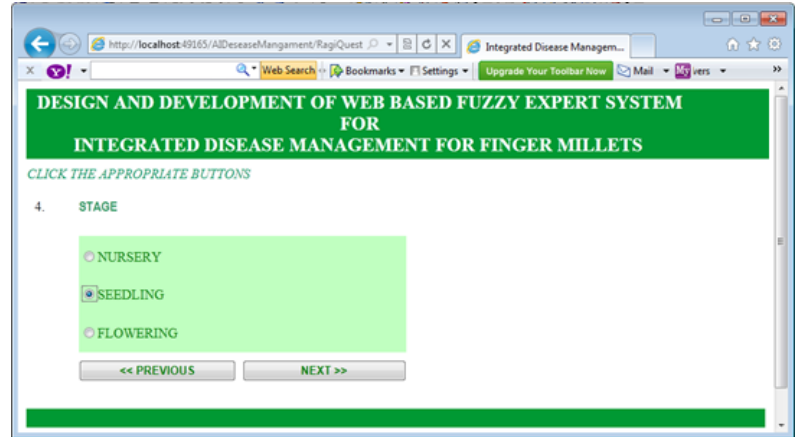

Figure 7: Identification of the Stage

Finally, the picture of the appearance of the infected crop is displayed as a final confirmation.

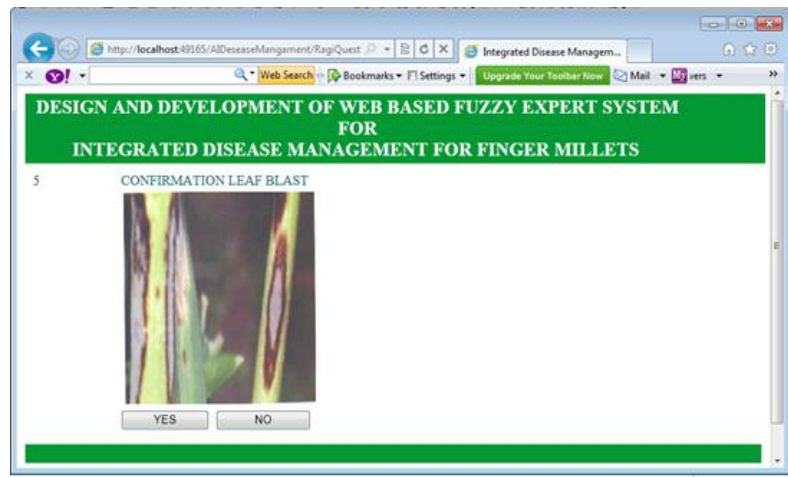

Figure 8: Infected Crop

And following which the recommendations for the disease and the tips are mentioned

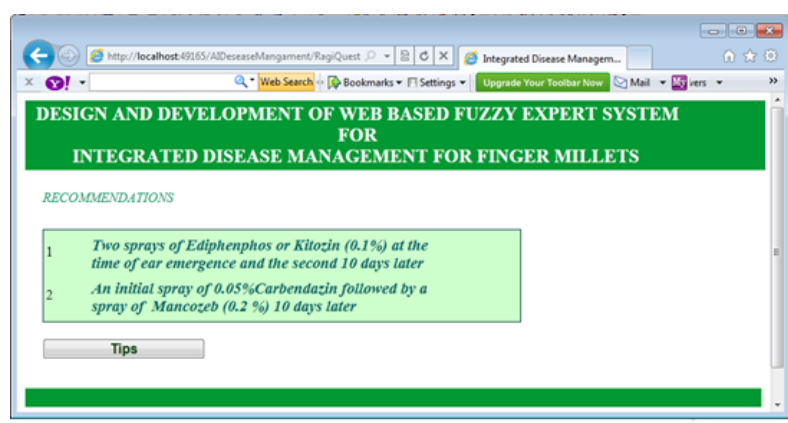

Figure 9: Recommendations suggested by the system

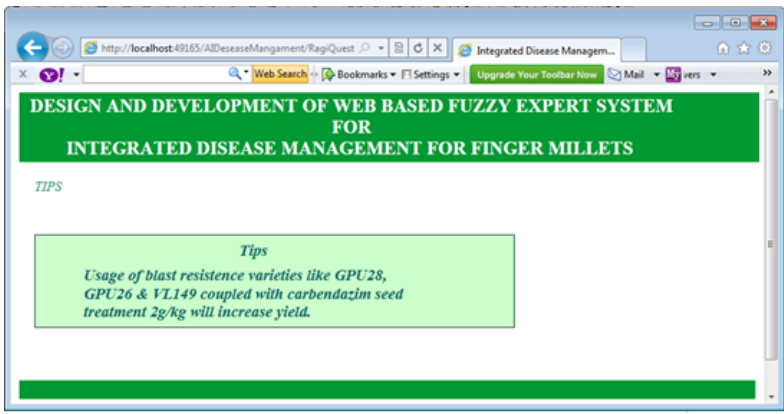

Figure 10: Tips from the System 


\section{DEFUZZIFICATION OF PATHOMETRY IN IDM}

Pathometry is the branch of plant pathology that deals with quantification or measuring plant disease. Defuzzification plays an important role in the implementation of a fuzzy system since the crisp value generated best represents the possibility distribution of all possible fuzzy control outputs [7].

There are three different ways suggested for the calculation of disease quantification. They are:

- Disease incidence,

- Disease severity and

- $\quad$ Yield loss

Of all the three measures, disease incidence is considered keeping in mind that the farmer has to give simple inputs which can be done by observation. They provide a basis for probabilistic inference, to calculate the changes in probabilistic belief as new evidence is obtained [8]. However, their use in real problem domains is hampered by the difficulties facing the construction of such belief networks, particularly in domains where neither sufficient data nor human expertise is available [10].

Disease incidence is defined as the number or proportion of plant units diseased. The equation to calculate is given by:

$$
\begin{gathered}
\text { Percent Disease Incidence } \\
(\text { PDI })
\end{gathered}=\frac{\text { Number of infected plants }}{\text { Total number of units assessed }} * 100
$$

Based on the value of PDI grades are assigned as follows:

- $\quad$ Disease diagnosed: Blast

- Affected part: Leaf

\begin{tabular}{|c|l|l|}
\hline RANK & $\begin{array}{c}\text { PERCENTAGE OF LEAF } \\
\text { AFFECTED AREA }\end{array}$ & \multicolumn{1}{|c|}{ REACTION } \\
\hline 0 & $\begin{array}{c}\text { No symptoms on the } \\
\text { leaves }\end{array}$ & Immune \\
\hline 1 & $<1 \%$ & Highly resistant \\
\hline 2 & $1-5 \%$ & Resistant \\
\hline 3 & $5-25 \%$ & $\begin{array}{l}\text { Moderately } \\
\text { resistant/susceptible }\end{array}$ \\
\hline 4 & $25-50 \%$ & Susceptible \\
\hline 5 & $>50 \%$ & Highly susceptible \\
\hline
\end{tabular}

Table 1: Defuzzification rules to evaluate the percentage of the severity of the disease

\section{CONCLUSION}

Though there are many methodologies available to identify the disease and evaluate the severity, based on which the recommendations can be made, the most commonly used is the experience of the farmer and the knowledge of the agriculturist. The expert system that is been developed is a blend of both the above mentioned factors along with the application of technological advancements. Since the expert system has a module of acquiring new knowledge, the new breed of diseases that attack the crop can also be recorded.
The system thus developed can also be extended to incorporate various other modules like integrated pest management, soil management and fertilizers management making it a total solution provider for in all aspect and hence increasing the yield.

\section{ACKNOWLEDGEMENTS}

We extend our sincere thanks to the Dr. Nagaraja, Pathologist and Dr. Jayarame Gowda, Geneticist of Project Coordination cell, All India Coordinated Small Millets Improvement Project, ICAR, UAS, GKVK, Bangalore for their valuable guidance and suggestion given throughout. Without their encouragement and support, this research work would have been incomplete.

\section{REFERENCES}

[1] Shouyi Liu; Dongling Wei; Jiajun Liu; , "Agricultural information engineering research," Computer Science and Service System (CSSS), 2011 International Conference on , vol., no., pp.2011-2015, 27-29 June 2011

[2] Shrivastava, P.; Satpathy, S.K.; Nagwanshi, K.K.; "Development of an Expert System as Spiritual Guru," Machine Learning and Computing (ICMLC), 2010 Second International Conference on , vol., no., pp.166168, 9-11 Feb. 2010

[3] Zhiqing Zhu; Rongmei Zhang; Jieli Sun; , "Research on GIS-Based Agriculture Expert System," Software Engineering, 2009. WCSE '09. WRI World Congress on , vol.3, no., pp.252-255, 19-21 May 2009

[4] Zelu Jia; , "An Expert System Based on Spatial Data Mining Used Decision Tree for Agriculture Land Grading," Intelligent Computation Technology and Automation, 2009. ICICTA '09. Second International Conference on , vol.4, no., pp.142-145, 10-11 Oct. 2009

[5] Tang Huili; Ye Jiyao; Zhou Lianqing; Shi Zhou; "Agriculture Disease Diagnosis Expert System Based on Knowledge and Fuzzy Reasoning: A Case Study of Flower," Fuzzy Systems and Knowledge Discovery, 2009. FSKD '09. Sixth International Conference on , vol.3, no., pp.39-43, 14-16 Aug. 2009

[6] Mutalib, S.; Azlan, N.M.; Yusoff, M.; Rahman, S.A.; Mohamed, A.; , "Plant Selection System," Computational Sciences and Its Applications, 2008. ICCSA '08. International Conference on , vol., no., pp.33-38, June 30 2008-July 32008

[7] Mogharreban, N.; Dilalla, L.F.; , "Comparison of Defuzzification Techniques for Analysis of Non-interval Data," Fuzzy Information Processing Society, 2006. NAFIPS 2006. Annual meeting of the North American , vol., no., pp.257-260, 3-6 June 2006

[8] Ding Wei-long; Xiong Fan-lun; Cheng Zhi-jun; , "Study and implementation of the expert system for greenhouse tomato planting," Information Technology and Applications, 2005. ICITA 2005. Third International Conference on , vol.1, no., pp. 325- 329 vol.1, 4-7 July 2005

[9] Weizhe Feng; Yanqing Duan; Zetian Fu; , "A Case Study of the Role of Agricultural Knowledge Broker," Wireless Communications, Networking and Mobile Computing, 2007. WiCom 2007. International Conference on , vol., no., pp.5659-5662, 21-25 Sept. 2007 
[10] Yiqun Gu; Peiris, D.R.; Crawford, J.W.; NcNicol, J.W.; Marshall, B.; Jefferies, R.A.; , "An application of belief networks to future crop production," Artificial Intelligence for Applications, 1994., Proceedings of the Tenth Conference on , vol., no., pp.305-309, 1-4 Mar 1994

[11] Saint-Joan, D.; Desachy, J.; , "A fuzzy expert system for geographical problems: an agricultural application," Fuzzy Systems, 1995. International Joint Conference of the Fourth IEEE International Conference on Fuzzy Systems and The Second International Fuzzy Engineering Symposium., Proceedings of 1995 IEEE
International Conference on , vol.2, no., pp.469-476 vol.2, 20-24 Mar 1995

[12] Technology For Increasing Finger Millet And Other Small Millets Production In India Project Coordination Cell,Indian Council of Agricultural Research ,University of Agricultural Sciences, GKVK Campus,Bangalore 560065

[13] Compendium of small millets diseases - Project Coordination Cell,Indian Council of Agricultural Research ,University of Agricultural Sciences, GKVK Campus,Bangalore - 560065 . 